\title{
๖ The Response of Tropical Atmospheric Energy Budgets to ENSO*
}

\author{
MiCHAEL MAYER \\ Department of Meteorology and Geophysics, University of Vienna, Vienna, Austria \\ KEVIN E. TRENBERTH \\ National Center for Atmospheric Research, ${ }^{* *}$ Boulder, Colorado \\ LEOPOLD HAIMBERGER \\ Department of Meteorology and Geophysics, University of Vienna, Vienna, Austria \\ JOHN T. FASULLO \\ National Center for Atmospheric Research, ** Boulder, Colorado
}

(Manuscript received 18 September 2012, in final form 19 December 2012)

\begin{abstract}
The variability of zonally resolved tropical energy budgets in association with El Niño-Southern Oscillation (ENSO) is investigated. The most recent global atmospheric reanalyses from 1979 to 2011 are employed with removal of apparent discontinuities to obtain best possible temporal homogeneity. The growing length of record allows a more robust analysis of characteristic patterns of variability with cross-correlation, composite, and EOF methods. A quadrupole anomaly pattern is found in the vertically integrated energy divergence associated with ENSO, with centers over the Indian Ocean, the Indo-Pacific warm pool, the eastern equatorial Pacific, and the Atlantic. The smooth transition, particularly of the main maxima of latent and dry static energy divergence, from the western to the eastern Pacific is found to require at least two EOFs to be adequately described. The canonical El Niño pattern (EOF-1) and a transition pattern (EOF-2; referred to as El Niño Modoki by some authors) form remarkably coherent ENSO-related anomaly structures of the tropical energy budget not only over the Pacific but throughout the tropics. As latent and dry static energy divergences show strong mutual cancellation, variability of total energy divergence is smaller and more tightly coupled to local sea surface temperature (SST) anomalies and is mainly related to the ocean heat discharge and recharge during ENSO peak phases. The complexity of the structures throughout the tropics and their evolution during ENSO events along with their interactions with the annual cycle have often not been adequately accounted for; in particular, the El Niño Modoki mode is but part of the overall evolutionary patterns.
\end{abstract}

ə Denotes Open Access content.

\footnotetext{
* Supplemental information related to this paper is available at the Journals Online website: http://dx.doi.org/10.1175/JCLI-D-12-00681.s1

** The National Center for Atmospheric Research is sponsored by the National Science Foundation.
}

Corresponding author address: Michael Mayer, Department of Meteorology and Geophysics, University of Vienna, UZA II, Althanstr. 14, 1090 Vienna, Austria.

E-mail:mima@univie.ac.at

\section{Introduction}

The global atmospheric energy budget provides a fundamental basis for understanding and investigating the processes shaping the earth's climate system. Many scientific publications during recent decades have dealt with the quantification of the long-term mean vertical and horizontal energy fluxes within and over the boundaries of the atmosphere (e.g., Lorenz 1967; Peixoto and Oort 1992; Hantel et al. 2005; Trenberth et al. 2009). Recent estimates of the mean annual cycle of various atmospheric flux quantities in a globally and a zonally 
averaged framework, obtained from a variety of datasets and including an uncertainty assessment, are given in Fasullo and Trenberth (2008a,b).

Reanalyses, representing reprocessed gridded datasets of the three-dimensional atmospheric state covering a relatively long period of time, provide the possibility for estimating not only the climatological mean values but also the variability of budget terms such as radiative and turbulent fluxes as well as the divergence of energy transports (see, e.g., Trenberth and Stepaniak 2003a; Mayer and Haimberger 2012, hereafter MH12).

A major problem when exploring time variability with these datasets is their still imperfect temporal homogeneity, which is a consequence of the continually changing observing system (see, e.g., Chiodo and Haimberger 2010; Trenberth et al. 2011; MH12). For instance, in a zonally averaged framework, interannual variability of poleward total energy transports from reanalyses is relatively small (4\% of the climatological mean value; see MH12) and difficult to distinguish from spurious discontinuities in the data. Hence, the influence of El NiñoSouthern Oscillation (ENSO) on zonal mean tropical energy export is still hard to detect with current reanalyses, although it is well known that tropical energy budgets are strongly affected by ENSO (see, e.g., Trenberth et al. 2002a,b). Another consequence is the inability to properly analyze trends. However, MH12 found that the signal-tonoise ratio in computed energy budgets is much better when considering regional budgets separately (e.g., the eastern tropical Pacific region) rather than in a zonally averaged framework because strong east-west compensation of budget anomalies occurs in the tropics and reduces the magnitude of the signal.

The evolution of surface temperature, precipitation, outgoing longwave radiation, vertically integrated diabatic heating and divergence of atmospheric energy transports, and ocean heat content in the Pacific were documented using correlation and regression analysis for a limited period (1979-98) by Trenberth et al. (2002b) for contemporary relationships and with regard to the evolution using leads and lags in Trenberth et al. (2002a). They found a substantial diabatic component to the discharge and recharge of the ocean heat content during ENSO but most of the delayed warming outside of the tropical Pacific comes from persistent changes in atmospheric circulation forced from the tropical Pacific. A major part of the ocean heat loss to the atmosphere is through evaporation and is realized in the atmosphere as latent heating in precipitation, which drives teleconnections. In the tropical Pacific during large El Niño events, the anomalous divergence of the atmospheric total energy transports exceeds $50 \mathrm{~W} \mathrm{~m}^{-2}$ over broad regions for several months. The divergence of total energy therefore includes a strong latent energy component that in turn supplies the dry static energy (DSE) component so that there is considerable compensation between these two portions (Trenberth and Stepaniak 2003a). Here we build on those conclusions and use another $14 \mathrm{yr}$ of data to check for robustness of the conclusions.

It is a common approach to describe evolution of ENSO in terms of dependence of time and longitude of different fields. Many authors have shown longitude-time sections of fields such as sea surface temperature (SST), zonal wind stress, outgoing longwave radiation (OLR), or thermocline depth anomalies (see, e.g., Zebiak and Cane 1987; McPhaden 1999; Meinen and McPhaden 2000; Okumura and Deser 2010). MH12 first presented longitude-time variations of tropical total energy export across $30^{\circ} \mathrm{N}$ and $30^{\circ} \mathrm{S}$ for the period $1989-2010$ and found some intriguingly coherent longitude-time anomaly patterns related to ENSO, which we further investigate in this study.

Herein, we focus on the zonal structure and variability of the vertically integrated divergence of total atmospheric energy (TEDIV), latent heat as derived from the vertically integrated moisture divergence (LEDIV), and dry static plus kinetic energy transports (DSEDIV) in the tropical strip (defined as the region between $20^{\circ} \mathrm{N}$ and $20^{\circ} \mathrm{S}$ ). The variability of these divergences is of great interest, as it represents the integrated atmospheric response to the phases of the coupled ocean-atmosphere system, associated with varying surface fluxes and changes in atmospheric circulation (Trenberth et al. 2002a). For instance, variations of tropical moisture convergence inform us about regional strengthening/weakening of the Hadley circulation (Trenberth and Stepaniak 2003b). While previous studies (those cited herein and others) have delved into some aspects, new datasets have improved quality and resolution, as well as provided a much longer record. An understanding of this variability is motivated further by recent climate extremes, which while demonstrating a clear connection to ENSO are also likely to be influenced by a changing climate (see, e.g., Trenberth and Fasullo 2012).

After examining the climatological mean annual cycle and standard deviation of the zonally resolved energy divergence fields from 1979 to 2009 or to 2011, we investigate their interannual variations. For this purpose, we employ the three most recent third-generation reanalysis products European Centre for Medium-Range Weather Forecast (ECMWF) Interim Re-Analysis (ERA-I; Dee et al. 2011), Modern Era-Retrospective Analysis for Research and Application (MERRA; Rienecker et al. 2011), and National Centers for Environmental Prediction (NCEP) Climate Forecast System Reanalysis (CFSR; Saha et al. 2010). ERA-I and MERRA both are continually updated on a monthly basis and CFSR is available for 1979-2010. The period 
contains several strong ENSO events, which dominate the low-frequency variability of the divergence fields. In the subsequent sections we explore this variability employing cross-correlation, composite, and EOF analysis. This will lead to a description of the ENSO cycle in terms of atmospheric energy budgets. In the discussion, we reconcile these findings within existing ENSO theories.

\section{Data and methods}

The input data for this study are vertical radiative and turbulent fluxes as well as vertical integrals of horizontal energy transports and their divergence from three thirdgeneration reanalyses and a global precipitation dataset for comparison with the reanalyses fields.

ERA-I, the most recent reanalysis product of the ECMWF, was released in 2007 and has been constantly updated since then. In this study, data from 1979 to 2011 are used. This reanalysis has a horizontal resolution at $\mathrm{T} 255(\Delta x \simeq 80 \mathrm{~km})$ on 60 vertical hybrid model levels and employs a 12 -h four-dimensional variational data assimilation system.

CFSR, a product of the NCEP, is the first reanalysis employing a coupled atmosphere-ocean-land surfacesea ice model for data assimilation. The atmospheric model has a horizontal resolution at T382 $(\Delta x \simeq 50 \mathrm{~km})$ with 64 vertical levels and a three-dimensional variational data assimilation (3D-Var) system. Data used in this study cover the period 1979-2009.

MERRA is produced by the National Aeronautics and Space Administration (NASA) Global Modeling and Assimilation Office (GMAO). It employs the Goddard Earth Observing System atmospheric model and data assimilation system (GEOS-DAS) version 5 , which exhibits a $1 / 2^{\circ}$ latitude and $2 / 3^{\circ}$ longitude horizontal resolution on 72 vertical levels. For data assimilation, the Incremental Analysis Update (IAU) method is employed. This study employs MERRA data covering 1979-2011.

In addition to the fields from reanalyses, precipitation fields from the Global Precipitation Climatology Project (GPCP) version 2.2 (for details, see Huffman et al. 2009) are employed.

The vertically integrated divergence of total energy transport TEDIV $\left[=\left\langle\nabla \cdot F_{A}\right\rangle\right.$ in Eq. (1)] has to be balanced by the net radiation at the top of the atmosphere $\operatorname{Rad}_{\mathrm{TOA}}$, the net surface fluxes $F_{S}=\mathrm{LH}+\mathrm{SH}+\operatorname{Rad}_{S}$ (where LH denotes latent heat flux, SH denotes sensible heat flux, and $\operatorname{Rad}_{S}$ denotes the net radiation at the surface; all vertical fluxes are taken to be positive downward), and the vertically integrated tendency of atmospheric total energy $\partial\langle e\rangle / \partial t$, which gives

$$
\left\langle\nabla \cdot F_{A}\right\rangle=-\frac{\partial\langle e\rangle}{\partial t}-F_{S}+\operatorname{Rad}_{\mathrm{TOA}} .
$$

The vertically integrated divergence of moisture transport $\left[=\left\langle\nabla \cdot q v_{2}\right\rangle\right.$ in Eq. (2), with specific humidity $q$ and horizontal wind $v_{2}$ ] is balanced by evaporation $E$, precipitation $P$, and the tendency of total column water vapor $\partial\langle q\rangle / \partial t$. It can be written as

$$
\left\langle\nabla \cdot q v_{2}\right\rangle=-\frac{\partial\langle q\rangle}{\partial t}-P-E .
$$

Multiplication of Eq. (2) by the phase transition energy of vaporization $\mathrm{L}$ converts it to an equation for the divergence of latent heat transport (LEDIV) with units of watts per meter squared ( $29 \mathrm{~W} \mathrm{~m}^{-2}$ correspond to $1 \mathrm{~mm} \mathrm{day}^{-1}$ ). Physical constraints such as close to zero $\operatorname{Rad}_{\mathrm{TOA}}$ and $F_{S}$ or balanced $-P-E$ on the long-term global average are generally not satisfied in reanalyses, which is reflected in nonzero analysis increments [see Trenberth et al. (2011) and MH12 for a discussion of these issues].

The divergence terms in Eqs. (1) and (2) can be computed by either calculating the left (direct method) or right (indirect method) side of the equations, respectively. The direct estimate is calculated from analyzed fields of the atmospheric state variables, whereas the indirect estimate is obtained from 12-hourly forecasts of vertical fluxes and the energy tendency. The difference TEDIV - LEDIV yields

$$
\mathrm{DSEDIV}=-\frac{\partial\langle\mathrm{DSE}\rangle}{\partial t}+\mathrm{LP}-\mathrm{SH}-\mathrm{Rad}_{S}+\operatorname{Rad}_{\mathrm{TOA}} .
$$

Both the direct and the indirect method require a correction for mass inconsistencies in the forecast model in order to obtain meaningful results (see MH12 for a more detailed description of the methods). ERA-I results shown in this paper are exclusively obtained from the direct method. Energy divergences (also mass corrected) from CFSR were computed at the Climate Analysis Section (CAS) at the National Center for Atmospheric Research (NCAR) and obtained from the Climate Data Guide (https://climatedataguide.ucar. edu/). MERRA data used in this study have been provided by the GMAO at NASA Goddard Space Flight Center through the NASA Goddard Earth Sciences (GES) Data and Information Services Center (DISC) online archive. TEDIV and LEDIV from MERRA were calculated as proposed by Cullather and Bosilovich (2012). Additionally, we corrected MERRA energy divergences for mass inconsistencies in the same way as MH12 described for ERA-I (see also the supplemental material for a description of MERRA fields employed for mass correction).

Although large efforts are put into providing reanalysis data with best possible temporal homogeneity by using a fixed data assimilation system over the whole 
period covered and by employing variational bias correction (Dee and Uppala 2009), shifts of several watts per meter squared can still be found in the calculated energy budgets (see, e.g., MH12; Trenberth et al. 2011), stemming from shifts in the observing system. These inhomogeneities complicate the interpretation of anomalies when using one climatology over the whole data period. To reduce the effect of these shifts, we calculate split climatologies: that is, we use different climatologies before and after a major detected discontinuity. The ERA-I moisture budget shows several discontinuities related to changes in the Special Sensor Microwave Imager (SSM/I) data stream, while moisture budgets in MERRA and CFSR are more affected by Television and Infrared Observation Satellite (TIROS) Operational Vertical Sounder (TOVS)/Advanced TOVS (ATOVS) transitions in 1998 and 2001 (see Trenberth et al. 2011). Splitting the climatology results in the removal of artifacts but at the expense of possible reduction of true climate variability. As a compromise, we employ three split climatologies for all diagnostics in this study, 1979-91, 1992-2002, and 2003-11 for ERA-I data and 1979-98, 1999-2002 and 2003-present for MERRA and CFSR, in order to remove the two most influential discontinuities from each dataset (please see the supplemental material for a comparison showing the impact of this method). The method does not seem to have adverse effects and is clearly beneficial both in terms of eliminating spurious changes and in reconciling the results among the reanalyses.

\section{Results}

\section{a. Climatology and variability in the tropical strip}

The annual cycle of energy divergences (more precisely, divergences of vertically integrated horizontal energy transports) in a zonally averaged framework have been presented elsewhere for an earlier period (e.g., Trenberth and Stepaniak 2003a; Trenberth and Smith 2008; Fasullo and Trenberth 2008b). However, to set the stage for the following sections, here we present the zonally resolved annual cycle of the fields of TEDIV, LEDIV, and DSEDIV and the respective annual cycle of standard deviations.

Tropical $\left(20^{\circ} \mathrm{N}-20^{\circ} \mathrm{S}\right)$ average energy divergences show pronounced zonal structures with an imposed annual cycle. The total energy divergence TEDIV is generally positive all the year round except for the eastern Pacific (Fig. 1a). During boreal winter [DecemberFebruary (DJF)], energy export to the Northern Hemisphere $(\mathrm{NH})$ is strongest over the Indo-Pacific warm pool and the Atlantic, with values exceeding $70 \mathrm{~W} \mathrm{~m}^{-2}$. In austral winter [June-August (JJA)], highest TEDIV values (also around $70 \mathrm{~W} \mathrm{~m}^{-2}$ ) are found over the Indian Ocean, indicating this area as main region of energy export into the Southern Hemisphere (SH). Variability of TEDIV is relatively weak with standard deviations up to $20 \mathrm{~W} \mathrm{~m}^{-2}$ at most (Fig. 1d). Zonal mean TEDIV has a weak annual cycle, with values around $41 \mathrm{~W} \mathrm{~m}^{-2}$ in January decreasing to $35 \mathrm{~W} \mathrm{~m}^{-2}$ in August (plots of tropical average zonal mean annual cycles of the energy divergences as wells as their zonally averaged standard deviation are presented in the supplemental material).

Tropical latent energy divergence (Fig. 1b) features three major regions of convergence: (i) the Indo-Pacific warm pool with its high SSTs, strong convective activity, moist low-level inflow, and dry outflow aloft peaking in JJA with the Indian and Southeast Asian monsoon, and the landmasses of (ii) South America and (iii) Africa, where $P$ exceeds $E$ and thus negative LEDIV has to balance the water budgets. Regions of latent energy convergence extend farther to the east between November and March as the South Pacific convergence zone (SPCZ) is more pronounced at this time of the year, while latent energy convergence is more concentrated during the monsoon season. Regions of moisture divergence occur in the Pacific east of the date line and in the Atlantic where evaporation from the subtropical oceans exceeds precipitation related to the intertropical convergence zone (ITCZ). The LEDIV peak over the Indian Ocean in JJA is related to strong moisture transport to the monsoon regions. Zonal mean LEDIV varies between $-8 \mathrm{~W} \mathrm{~m}^{-2}$ in November and $+5 \mathrm{~W} \mathrm{~m}^{-2}$ in June. These low values indicate that, on the zonal average, almost all latent heat contained in atmospheric water vapor evaporated between $20^{\circ} \mathrm{N}$ and $20^{\circ} \mathrm{S}$ is used for driving the Hadley circulation and comparatively small amounts of moisture are exported from the tropical strip. Months of highest LEDIV variability (up to $50 \mathrm{~W} \mathrm{~m}^{-2}$ standard deviation in regions with LEDIV values around $-50 \mathrm{~W} \mathrm{~m}^{-2}$ like the Indo-Pacific warm pool during DJF; see Fig. 1e) do not coincide with highest absolute values (JJA). This high DJF variability is related to ENSO as will be seen later. Especially high LEDIV values in JJA related to the monsoons show comparatively low variability $\left(10-20 \mathrm{~W} \mathrm{~m}^{-2}\right)$.

When neglecting the tendency term (monthly means usually $<2 \mathrm{~W} \mathrm{~m}^{-2}$ in the area of interest), DSEDIV equals the diabatic heating of the atmosphere [sometimes referred to as $Q_{1}$, such as in Trenberth et al. (2002b)], which in turn is dominated by latent heating and radiative cooling. Highest values $\left(>100 \mathrm{~W} \mathrm{~m}^{-2}\right)$ are found over the Indo-Pacific warm pool (Fig. 1c), with strong convective precipitation and therefore low OLR values, leading to weak radiative cooling of the atmosphere. Weaker radiative cooling means stronger DSEDIV. In contrast, little precipitation and generally clear skies over large parts of the eastern tropical Pacific favor 


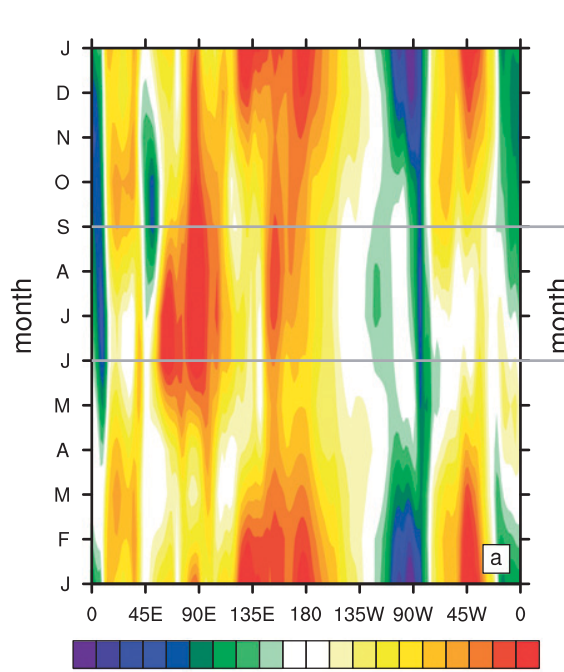

$\begin{array}{llllllllll}-20 & -10 & 0 & 10 & 20 & 30 & 40 & 50 & 60 & 70\end{array}$ $\mathrm{Wm}^{-2}$

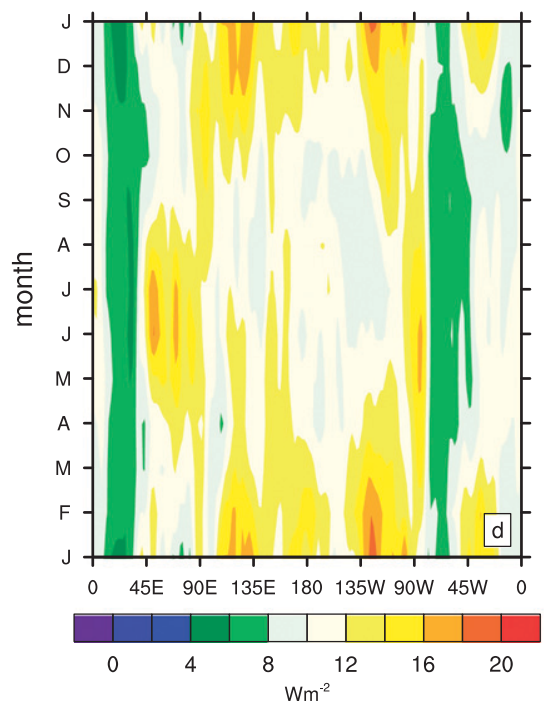

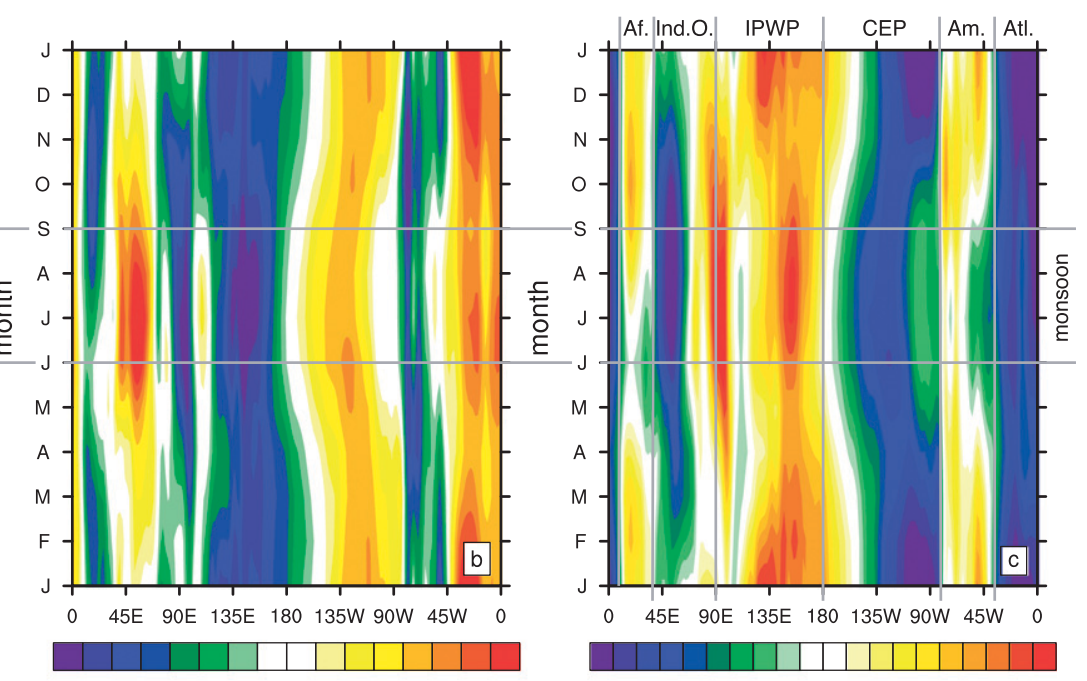

$\begin{array}{llllllll}-70 & -50 & -30 & -10 & 10 & 30 & 50 & 70\end{array}$

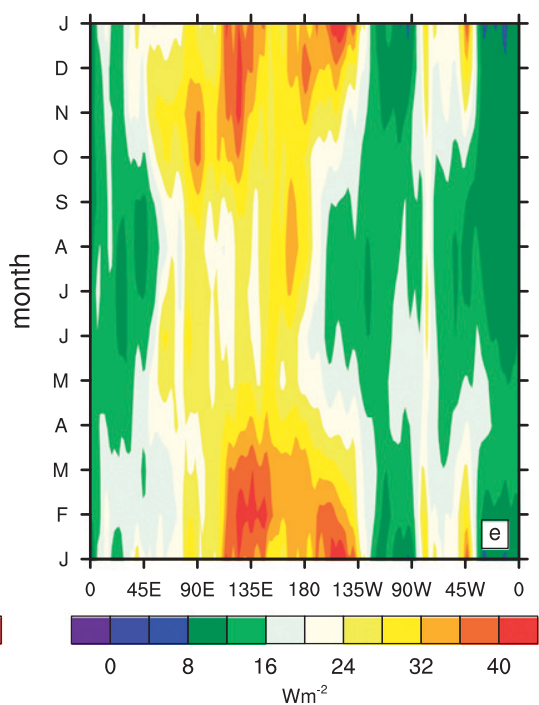

$\begin{array}{lllllllllll}-40 & -20 & 0 & 20 & 40 & 60 & 80 & 100 & 120 & 140\end{array}$

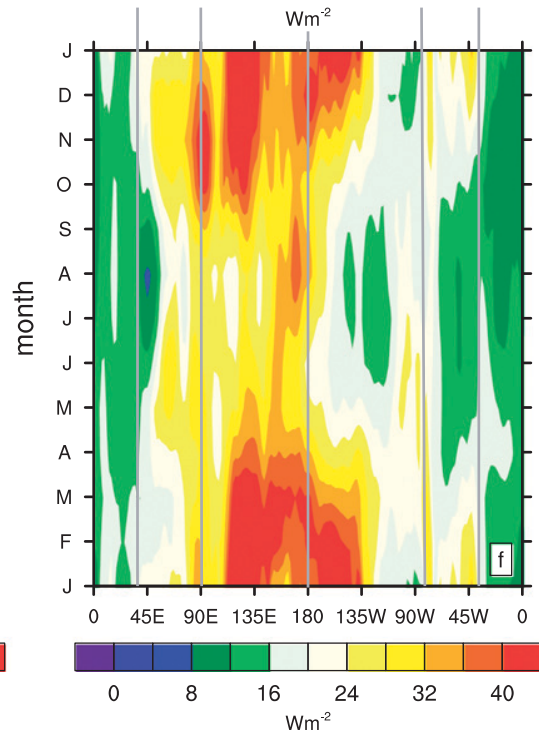

FIG. 1. Annual cycle of tropical $\left(20^{\circ} \mathrm{N}-20^{\circ} \mathrm{S}\right)$ average monthly mean (a) TEDIV, (b) LEDIV, and (c) DSEDIV. Annual cycle of monthly standard deviation of (d) TEDIV, (e) LEDIV, and (f) DSEDIV, based on ERA-I. Regions referred to in the text are indicated by gray lines: Africa (Af.), Indian Ocean (Ind. O.), Indo-Pacific warm pool (IPWP), central-eastern Pacific (CEP), South America (Am.), and Atlantic (Atl.); Southeast Asian and Indian monsoon seasons are also indicated.

strong radiative cooling to space, balanced by convergence of dry static energy over large regions. Analogous to LEDIV, we find the broadening of positive DSEDIV values over the Indo-Pacific warm pool between November and March as well as the concentration during the monsoon season. DSEDIV standard deviation (Fig. 1f) is very similar to LEDIV standard deviation. Hence, the structure of DSEDIV variability is strongly coupled with the structure of latent heat release variability related to LEDIV variability in the tropics. Zonally averaged DSE export from the tropics varies from $46 \mathrm{~W} \mathrm{~m}^{-2}$ in November to $31 \mathrm{~W} \mathrm{~m}^{-2}$ in June and thus dominates total energy export from the tropics.
Comparison of the average annual cycle of LEDIV from the three employed reanalyses reveals considerable differences exceeding $20 \mathrm{~W} \mathrm{~m}^{-2}$ in some months and regions (not shown), which is on a similar order as the results of Trenberth et al. (2011), who showed differences in freshwater flux $(P+E)$ between reanalyses. However, standard deviations from ERA-I and MERRA agree very well, with differences smaller than $\pm 5 \mathrm{~W} \mathrm{~m}^{-2}$, while CFSR standard deviations differ by up to $10 \mathrm{~W} \mathrm{~m}^{-2}$ from the two others. Despite these rather large differences in the climatologies, we will show good agreement of the reanalyses in terms of interannual anomalies in section $3 \mathrm{~d}$. 

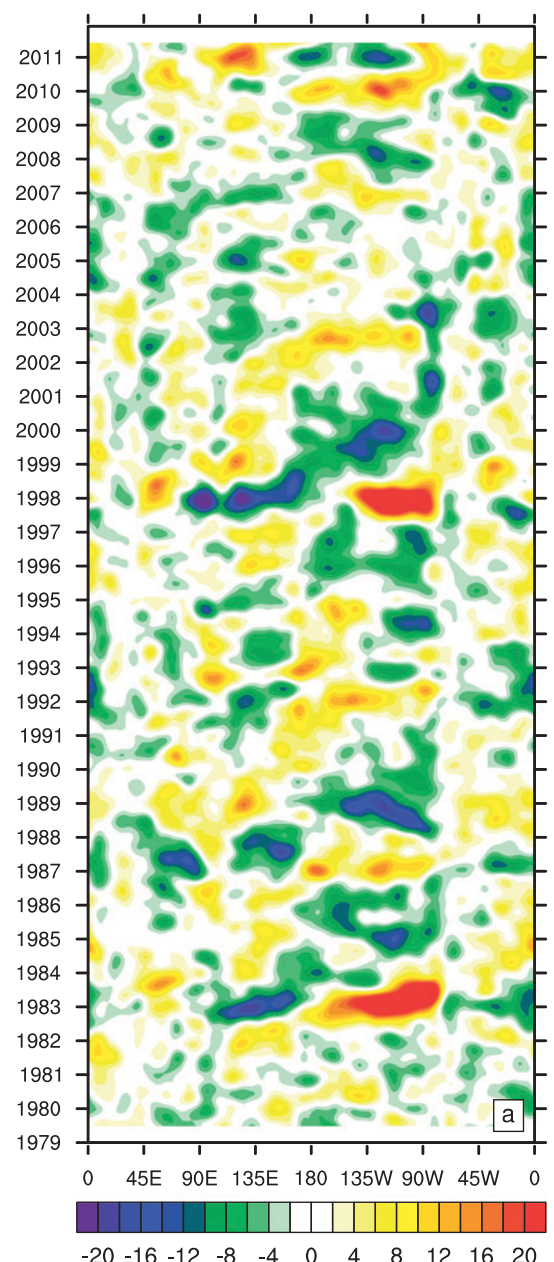

$\mathrm{Wm}^{-2}$
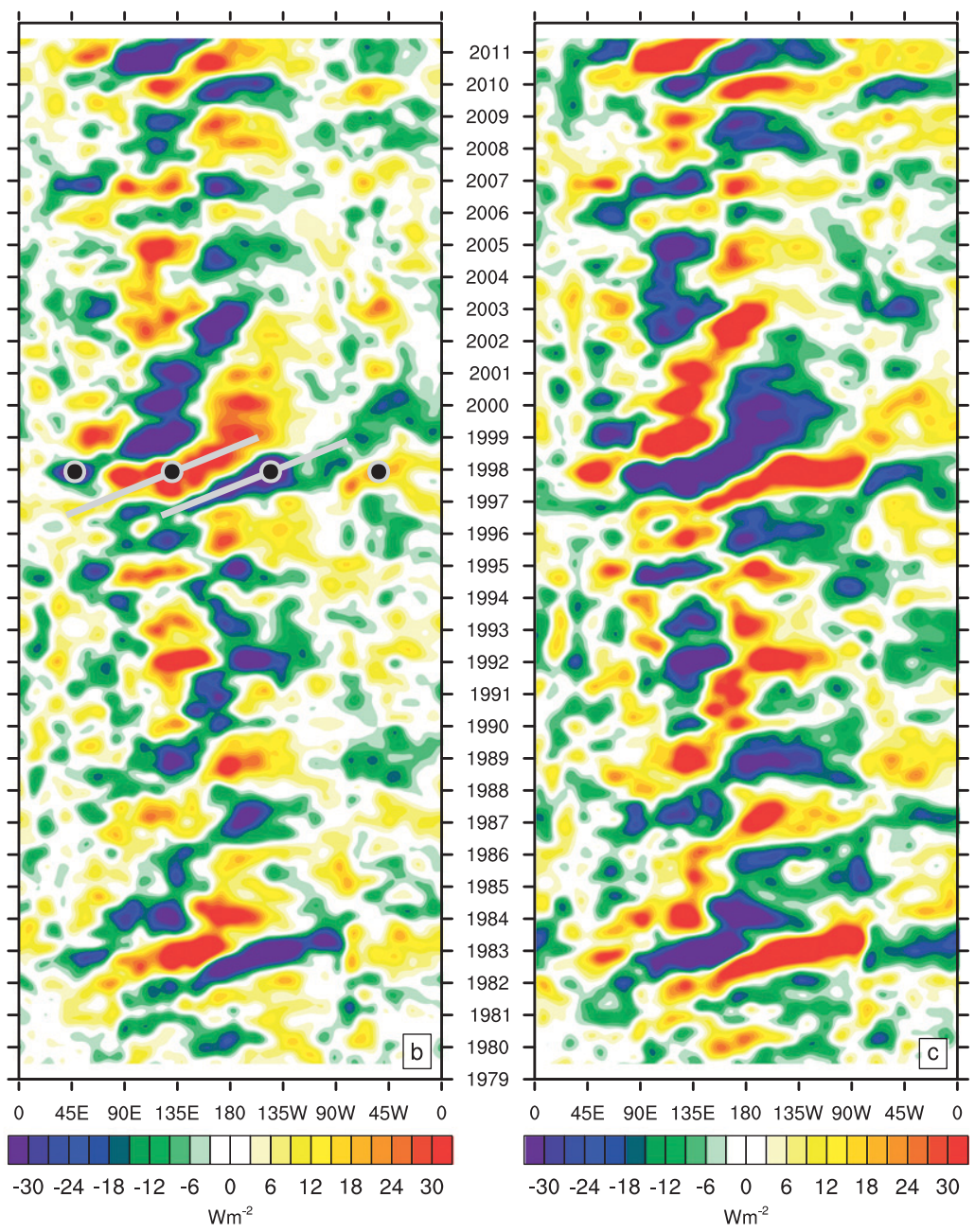

FIG. 2. Longitude-time Hovmöller plots of smoothed monthly anomalies of tropical (a) TEDIV, (b) LEDIV, and (c) DSEDIV from ERA-I. Filled circles in (b) indicate the quadrupole anomaly response to the 1997/98 El Niño event. Gray lines indicate the eastward propagation of the main anomaly maxima.

\section{b. Longitude-time variability of the divergence fields}

Longitude-time variability of TEDIV, LEDIV, and DSEDIV from ERA-I is depicted in Fig. 2. Anomalies of monthly averages are shown, averaged between $20^{\circ} \mathrm{N}$ and $20^{\circ} \mathrm{S}$ with a $2^{\circ}$ zonal resolution. After calculation of these area averages, a 13-weight low-pass filter (weights are 1-6-19-42-71-96-106-96-71-42-19-6-1; see Trenberth et al. 2007) is applied to both zonal and time dimensions. This procedure is carried out for all fields shown in the following sections to emphasize large-scale interannual variations.

Tropical energy budgets exhibit strong anomalies with a pronounced zonal structure. TEDIV anomalies (Fig. 2a) can reach more than $\pm 20 \mathrm{~W} \mathrm{~m}^{-2}$ over large regions while LEDIV and DSEDIV anomalies can exceed $\pm 30 \mathrm{~W} \mathrm{~m}^{-2}$. For LEDIV (Fig. 2b) and DSEDIV (Fig. 2c), a pronounced quadrupole structure can be observed during ENSO extreme phases. During warm ENSO events (e.g., in 1982/83, 1986/87, 1991/92, 1994/95, 1997/98, 2002/03, and 2009/10), LEDIV shows negative anomalies (i.e., less divergence or more convergence) over the eastern Pacific region and to a smaller extent over the Indian Ocean, while positive LEDIV anomalies are found over the Indo-Pacific warm pool and the Atlantic. DSEDIV shows the same structures but of the opposite sign. DSEDIV anomalies are thus dominated by anomalous latent heat release stemming from precipitation related to anomalous LEDIV. The same applies for cold events (e.g., 1988/89, 1996/97, 2008/09, and 2010/11) but with the opposite sign. This anticorrelation is also apparent in a zonally averaged framework (see Fig. 9 in Trenberth and Smith 2008).

The amplitude of DSEDIV anomalies tends to exceed the amplitude of LEDIV anomalies because there is a sizeable additional contribution from anomalous 

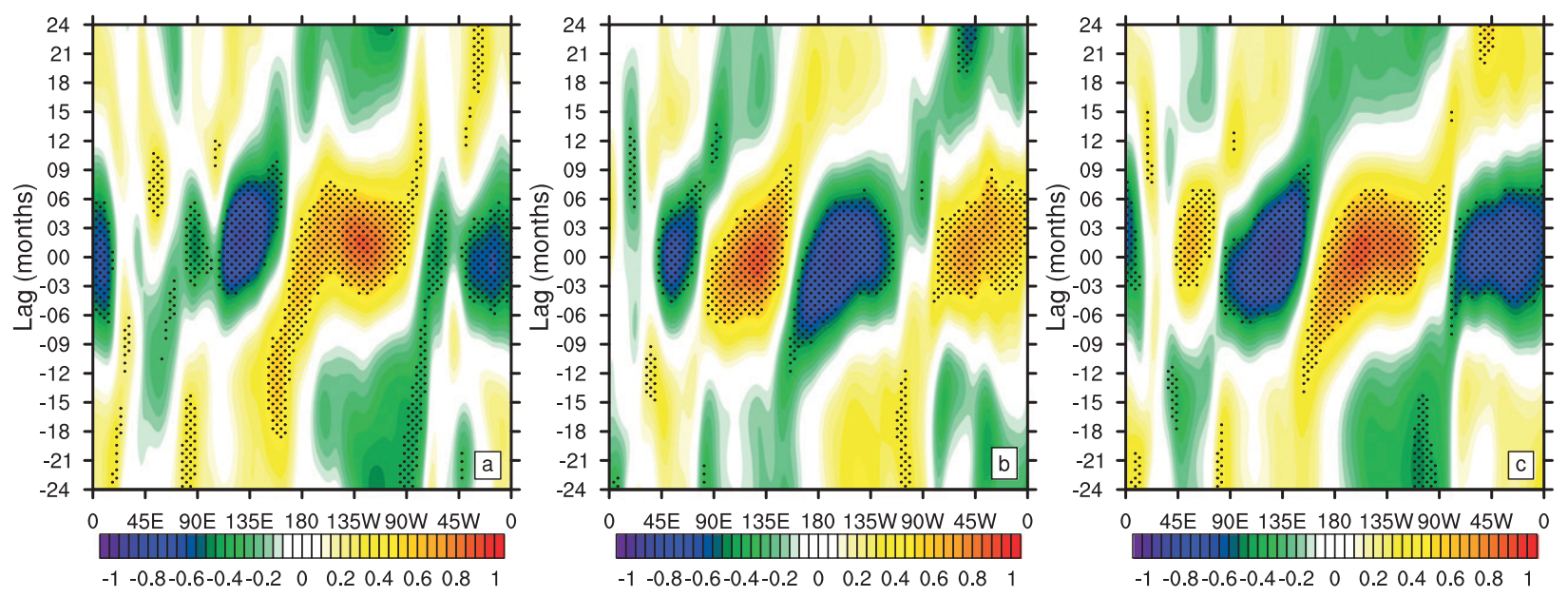

FIG. 3. Cross correlations of (a) TEDIV, (b) LEDIV, and (c) DSEDIV with Niño-3.4; stippling denotes correlations with significance $>95 \%$. Cross-correlation coefficients of all fields reach values up to \pm 0.9 .

radiative flux convergence, which usually is in phase with LEDIV anomalies. A more detailed explanation for this will be given in section $3 \mathrm{~d}$.

Diabatic heating (cooling) is accompanied by rising (sinking) motion (i.e., diabatic heating drives thermally direct circulations). Hence, the observed quadrupole structure in DSEDIV and LEDIV is the signature of circulation anomalies in the vertical equatorial plane, which is one manifestation of the atmospheric bridge, discussed in detail by Alexander et al. (2004).

Total energy divergence (Fig. 2a) exhibits a structure similar to DSEDIV, but the anomalies are smaller by about $50 \%$. Anomalies over the Indian Ocean and the Atlantic are small (usually $<10 \mathrm{~W} \mathrm{~m}^{-2}$ ). The most prominent feature is the ENSO-related dipole structure with negative (positive) values over the Indo-Pacific warm pool and positive (negative) values over the eastern equatorial Pacific during warm (cold) ENSO events (already described in MH12). As $\operatorname{Rad}_{\mathrm{TOA}}$ shows weak sensitivity to tropical SST (Trenberth et al. 2010) and $\partial\langle e\rangle / \partial t$ anomalies are small (analyzed tendencies $<5 \mathrm{~W} \mathrm{~m}^{-2}$ ), observed TEDIV anomalies are mainly associated with variations in $F_{S}$ (radiative and turbulent fluxes). Thus, a positive TEDIV anomaly corresponds to either stronger than normal energy gain from the ocean or weaker than normal energy loss. Figure 2a shows clearly that there is always strong zonal compensation in TEDIV anomalies over the Pacific Ocean, and this is related to the Walker circulation. However, eastern Pacific TEDIV anomalies usually are not fully offset, and thus their sign determines the sign of the zonally averaged tropical Pacific TEDIV anomaly.

Another conspicuous feature, most noticeable from DSEDIV and LEDIV in Figs. 2b and 2c, is the coherent anomaly pattern during the transitions between El Niño and La Niña, which is pervasive in the tropics. For example, in mid-1981, with weak La Niña conditions prevailing, a relatively weak quadrupole structure (as described above) is found with positive DSEDIV anomalies over and even slightly to the west of the Indo-Pacific warm pool. In the subsequent months and development of the strong 1982/83 El Niño, the DSEDIV anomalies shift eastward and reach the coast of South America, where they coincide with the peak of the event in late 1982. A similar evolution can be seen in LEDIV, with opposite sign, and in TEDIV (though much weaker). The evolution of the 1997/98 El Niño shows very similar structures. Hence, the decrease of trade winds, a fundamental feature of the El Niño onset phase (Clarke 2008), is associated with a gradually eastward shifting pattern of energy budget anomalies. These coherently propagating patterns can also be observed during the development of cold ENSO events, such as the major La Niña in 2010/11. In the subsequent sections, we will show that these transitional patterns are robust features of ENSO evolution during the studied period.

\section{c. Cross correlations with ENSO}

To see the statistical significance of the patterns found from Figs. 2a-c, we compute cross correlations of TEDIV, LEDIV, and DSEDIV with the Niño-3.4 index (SSTs averaged in $5^{\circ} \mathrm{N}-5^{\circ} \mathrm{S}, 120^{\circ}-170^{\circ} \mathrm{W}$ ) at every longitude for lags between -24 and +24 months. Cross correlation of total energy divergence with Niño-3.4 (Fig. 3a) shows the pronounced dipole structure over the tropical Pacific in phase with Niño-3.4. Over the Atlantic, additional significant anomalies of opposite sign to the eastern Pacific TEDIV anomalies occur. The strip of positive 
correlations propagates eastward and achieves statistical significance near lag -18 (negative lags mean Niño-3.4 is leading) and is mainly related to the phase transition from warm to cold events, as can be seen, for instance, in Fig. 2a after the 1982/83 and 1997/98 El Niños (cooling SSTs coinciding with negative TEDIV anomalies).

The quadrupole response of LEDIV and DSEDIV to ENSO, described in section $3 b$, is confirmed by significant correlations at lag 0 (Figs. 3b,c), consistent with results shown in Fig. 10 of Trenberth et al. (2002a). Eastward propagation of anomalies during developing and declining ENSO events is also indicated by the cross correlations, achieving significant values near lag -12 .

Finding propagating features also in TEDIV indicates that these patterns are not only a result of circulation changes leading to redistribution of latent heating and thus compensating anomalies of LEDIV and DSEDIV but also associated with net surface flux anomalies. Crosscorrelation patterns at small lags of all three fields in Fig. 3 recur at larger positive and negative lags with opposite sign. This is consistent with the negative autocorrelation of Niño-3.4 at lags larger (smaller) than $10(-10)$ months (the autocorrelation function of Niño-3.4 is shown in Fig. 6c, presented later).

\section{d. Composites}

As warm and cold ENSO events show asymmetry in length, spatial structure, and their evolution (e.g., Okumura and Deser 2010), it is not surprising that the propagating patterns described in section $3 \mathrm{~b}$ are not depicted very well in cross-correlation analysis (section $3 \mathrm{c})$. We considered the spatiotemporal evolution of the five strongest warm ENSO events (in terms of maximum Niño-3.4 anomalies) after 1978: namely, 1982/83, $1986 / 87,1991 / 92,1997 / 98$, and 2009/10. As the 2009/10 event is not covered by our CFSR and MERRA data and thus comparison between the reanalyses is impossible, we show a composite analysis including only the three strongest warm ENSO events (1982/83, 1991/92, and 1997/98) in this section. The evolution of LEDIV for the five single El Niños as well as a five-event composite from ERA-I data is presented in the supplemental material. Prior to compositing, the anomaly fields for the single events have been centered at the month of the respective SST anomaly peaks.

Figures $4 \mathrm{a}-\mathrm{c}$ show LEDIV composites from ERA-I, CFSR, and MERRA, respectively. All three reanalyses show negative LEDIV anomalies between $90^{\circ}$ and $130^{\circ} \mathrm{E}$ around $15-18$ months prior to the peak of the El Niños (in fact, at this time there can be seen a weak quadrupole structure as described in section $3 \mathrm{~b}$ ). This pattern then propagates eastward gradually, reaching the central and eastern Pacific at the peak of the El
Niños. At that time, the quadrupole structure shows up with anomalies exceeding $\pm 25 \mathrm{~W} \mathrm{~m}^{-2}$. During the decline of the event, the quadrupole again shifts eastward, so that, more than a year after the event peak, negative LEDIV anomalies reach the Atlantic. This coherent evolution in space and time is remarkable and much more prominent than in other fields such as SST (Fig. 4g). The three reanalyses agree quite well, but difference plots of the LEDIV composites (not shown) reveal differences of up to $10 \mathrm{~W} \mathrm{~m}^{-2}$ at times of largest anomalies. This is probably mainly related to varying magnitudes of analyzed moisture anomalies in the three datasets rather than their representation of circulation anomalies, as Trenberth et al. (2011) already found when comparing the climatologies of moisture transports. The qualitative agreement of longitude-time variability of total column water vapor in the three reanalyses is good, but there are considerable discrepancies in magnitude (not shown). We also investigated a possible connection between differing SST values used in the three reanalyses and differences in LEDIV anomalies. SST anomaly differences are on the order of $0.1 \mathrm{~K}$ over large regions, with CFSR SSTs being generally higher than those from ERA-I and MERRA prior to 1981 and after 2002. LEDIV and SST anomaly differences between the datasets are indeed significantly correlated in many regions along the equator, but correlations are much weaker and mostly insignificant when considered over the regions of our interest $\left(20^{\circ} \mathrm{N}-20^{\circ} \mathrm{S}\right)$.

DSEDIV (Fig. 4e) shows a picture very similar to LEDIV, but of reversed sign. The magnitudes are even larger, indicating some contribution from the convergence of radiative fluxes, $\operatorname{Rad}_{S}-\operatorname{Rad}_{\text {TOA }}$ [see Eq. (3) and Fig. 4h]. This is the case because enhanced moisture flux convergence usually is accompanied by higher than normal total column water vapor and cloud coverage. The higher than normal cloud tops lead to stronger reflection of incoming solar radiation (RSR) and lower OLR. However, in sum $\operatorname{Rad}_{\mathrm{TOA}}$ anomalies are small compared to $\operatorname{Rad}_{S}$ anomalies. Inspection of anomalous upwelling and downwelling shortwave and longwave fluxes at the surface from ERA-I (not shown) reveals that the largest contribution to $\operatorname{Rad}_{S}$ comes from reduced downwelling solar radiation (mainly due to increased RSR). Stronger than normal upwelling longwave radiation at the surface (due to higher SSTs) is largely offset by stronger than normal downwelling longwave radiation (due to increased moisture content in the atmosphere). In sum, these effects lead to a negative $\operatorname{Rad}_{S}$ anomaly. Hence, the result of approximately unaltered net radiation at TOA $\left(\operatorname{Rad}_{\text {TOA }}^{\prime} \simeq 0\right)$ and a negative net surface radiation anomaly $\left(\operatorname{Rad}_{S}^{\prime}<0\right)$ is reduced divergence of radiative fluxes (i.e., reduced radiative cooling; $\operatorname{Rad}_{S}^{\prime}-\operatorname{Rad}_{\mathrm{TOA}}^{\prime}<0$ ) in 

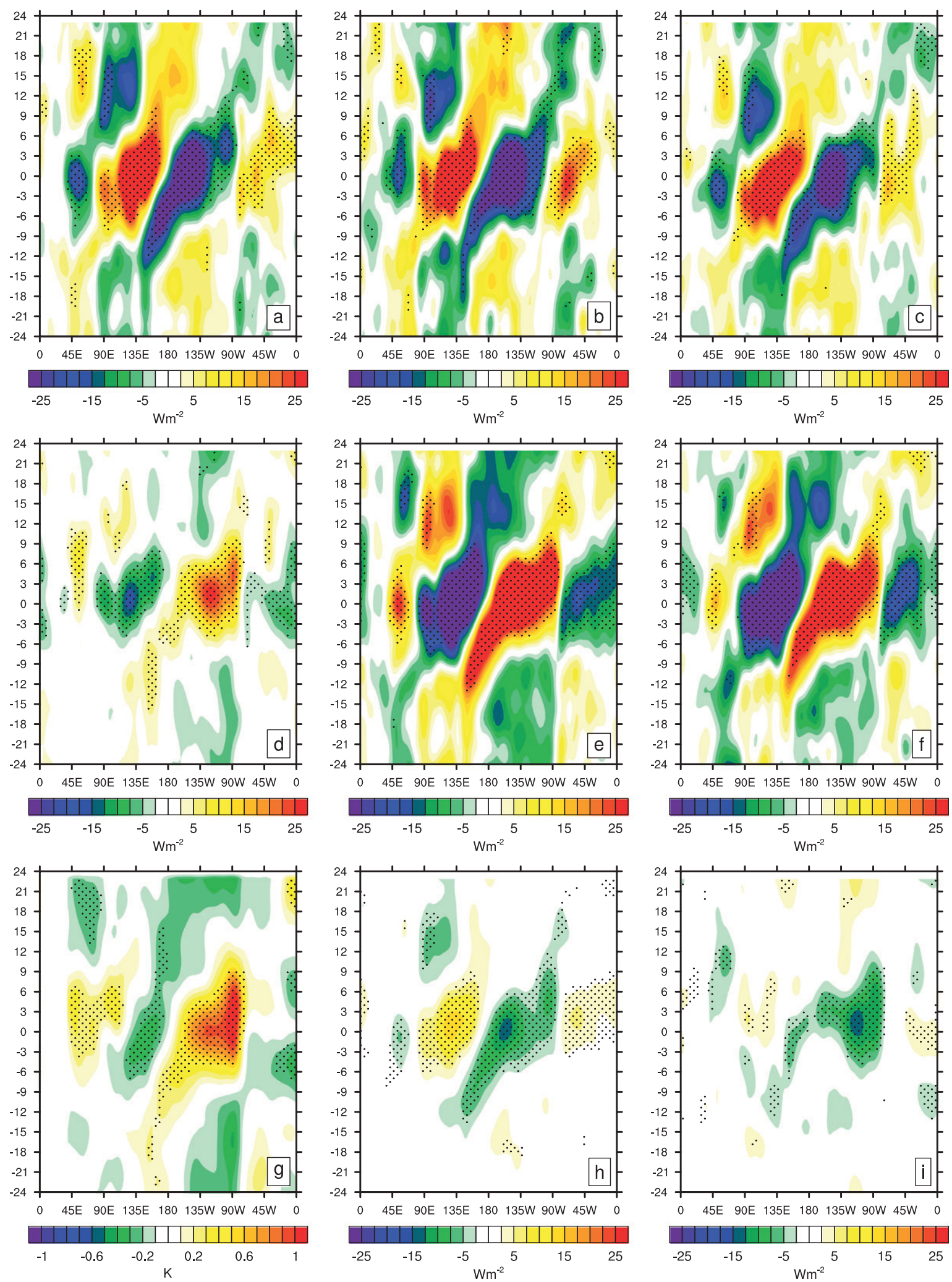

FIG. 4. Composites of anomalous tropical LEDIV from (a) ERA-I, (b) CFSR, and (c) MERRA; (d) TEDIV, (e) DSEDIV, (g) SSTs, (h) $\operatorname{Rad}_{S}-\mathrm{Rad}_{\mathrm{TOA}}$, and (i) LH from ERA-I; and (f) precipitation from GPCP, for the three strongest El Niños after 1978. Values on the $y$ axis denote months before (negative values) or after (positive values) the SST peak (according to Niño-3.4); stippling denotes anomalies with significance $>90 \%$. 

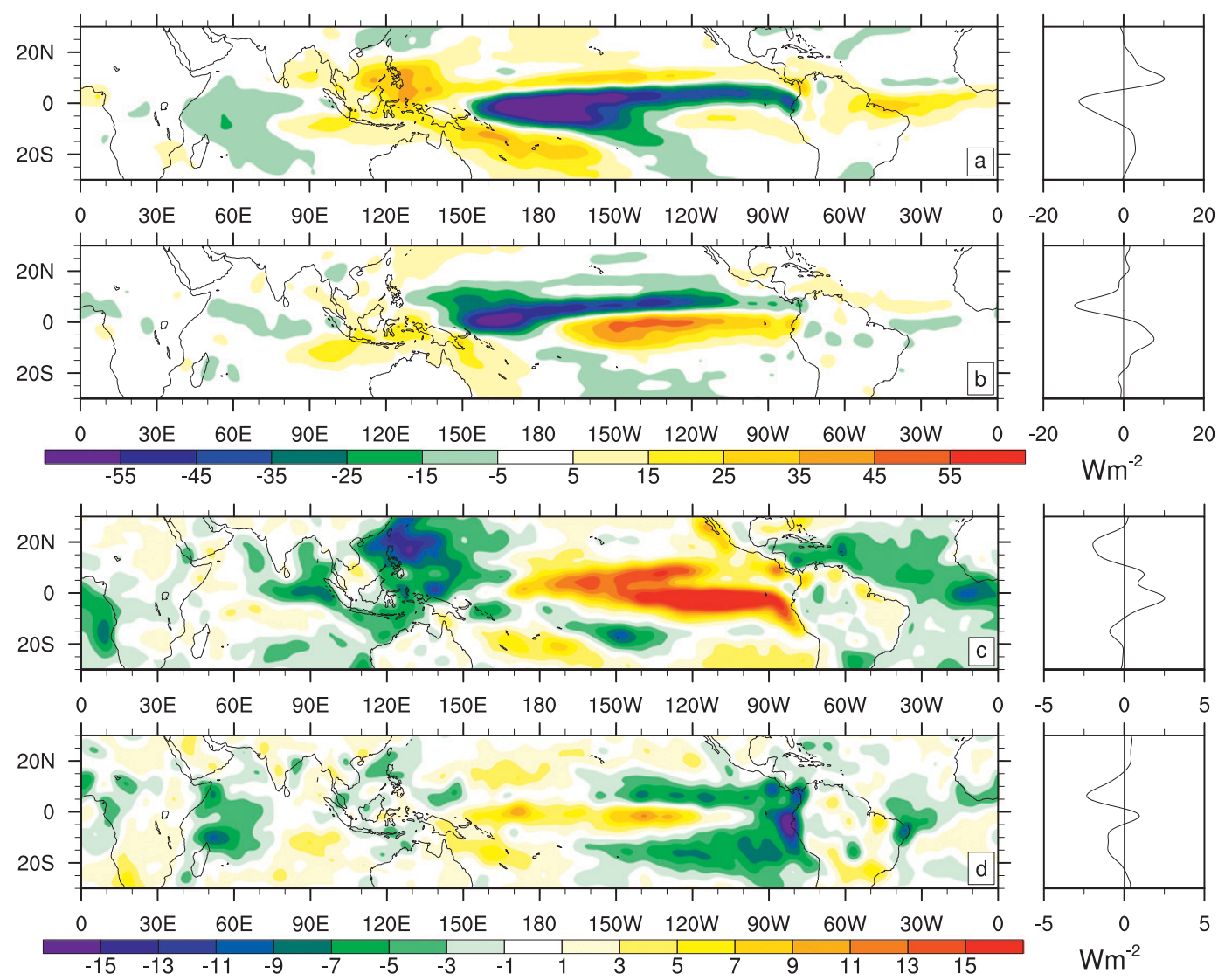

FIG. 5. (a) EOF-1 (28.1\% variance explained) and (b) EOF-2 (17.5\% explained) from ERA-I LEDIV; (c) EOF-1 (23.5\% explained) and (d) EOF-2 (8.9\% explained) from ERA-I TEDIV. Left panels show vertical integrals, right panels the respective zonal averages. All fields are multiplied by the standard deviation of the respective PCs; signs are chosen for warm ENSO events.

association with enhanced moisture flux convergence. The opposite is true for weaker than normal moisture flux convergence. While $\operatorname{Rad}_{S}$ anomalies alter the surface energy budget also during the transition period, anomalous evaporation is small more than a year from the SST peak (Fig. 4i). In agreement with Wallace and Shukla (1983) we find that by far the strongest contribution to ENSO-related precipitation anomalies stems from circulation (i.e., LEDIV) anomalies rather than evaporation anomalies. This is also confirmed by GPCP precipitation (Fig. 4f), which show structures in excellent agreement with LEDIV.

Compared to DSEDIV, TEDIV shows similar but weaker structures. Maximum anomalies reach $20 \mathrm{~W} \mathrm{~m}^{-2}$ over the eastern Pacific during the El Niño peaks, at times of maximum evaporation anomalies. The main difference in comparison to DSEDIV is the very weak transition pattern (anomaly $<5 \mathrm{~W} \mathrm{~m}^{-2}$ at $180^{\circ}$ around -6 months) from cold to warm ENSO state. We conclude that the propagating patterns seen from LEDIV and DSEDIV during the transition phase are associated with changes of the circulation while the signal in net surface flux and TEDIV is small at these times.

\section{e. EOF analysis}

An EOF analysis of tropical LEDIV, TEDIV, and DSEDIV is performed using a covariance matrix (fields on the full grid are first truncated at T42 and then weighted with the square root of the cosine of the latitude). We present the first two ERA-I LEDIV EOFs in Figs. 5a and 5b and the first two ERA-I TEDIV EOFs in Figs. $5 \mathrm{c}$ and $5 \mathrm{~d}$. The generally large structural differences between LEDIV and TEDIV EOFs in Figs. 5a-d are immediately apparent. They stem from the dominance of precipitation in LEDIV, while latent heat release (being just a conversion from latent to dry static energy) does not alter total energy.

The first LEDIV EOF (Fig. 5a) resembles canonical El Niño patterns, with enhanced moisture convergence along the equator from $140^{\circ} \mathrm{E}$ stretching to the coast of South America, surrounded by weaker than normal moisture convergence. The zonal mean (to the right of 

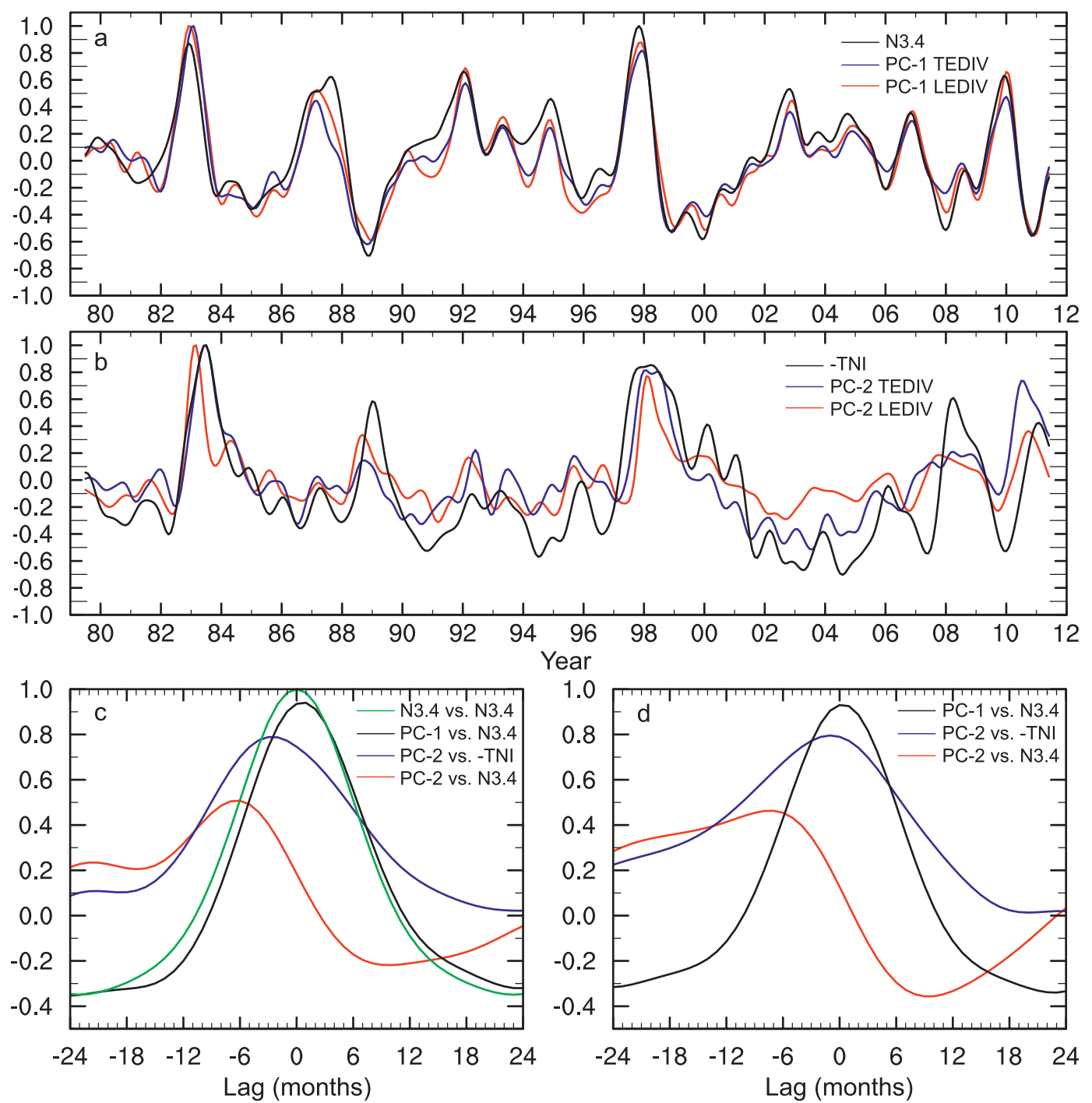

FIG. 6. Normalized (a) PC-1 of LEDIV and TEDIV as well as Niño-3.4 index, (b) PC-2 of LEDIV and TEDIV as well as -TNI and cross correlations of (c) LEDIV PCs and (d) TEDIV PCs with Niño-3.4 and - TNI (negative lag means respective $\mathrm{PC}$ is leading).

Fig. 5a) shows the well-known southward shift of the ITCZ and the northeast shift of the SPCZ (Clarke 2008). The quadrupole structure is also obvious, with its two major poles over the Indo-Pacific warm pool and central/eastern Pacific and its secondary poles over the Indian Ocean and Atlantic. LEDIV PC-1 and Niño-3.4 as well as their cross-correlation function are shown in Figs. $6 \mathrm{a}$ and $6 \mathrm{c}$, respectively. PC-1 is correlated 0.95 with Niño-3.4 at lag 1 month. Hence, this mode is almost synchronized with SSTs. Coherence with ENSO is also evident for the first EOFs of DSEDIV (not shown) and TEDIV (Figs. 6a,d).

EOF-2 (Fig. 5b) of LEDIV shows an area of enhanced moisture convergence along the equator, extending farther to the west than in EOF-1. The zonal average of
EOF-2 indicates a northward shift of the ITCZ. This pattern resembles El Niño Modoki (Ashok et al. 2007) SST patterns. Indeed, PC-2 is correlated 0.78 with the Trans-Niño Index [TNI; as defined in Trenberth and Stepaniak (2001); signs have been reversed to be positive for warm El Niño Modoki state] at lag -3 months (Figs. 6b,c). Thus, EOF-2 anomaly patterns occur prior to corresponding SST anomalies. Furthermore, PC-2 shows maximum correlation with Niño-3.4 at lag -6 , indicating that EOF-2 resembles the El Niño onset phase but may also arise from the required orthogonality of EOFs. EOF-2 of DSEDIV is very similar but with reversed signs (not shown). EOF analysis does reveal a pattern corresponding to El Niño Modoki for TEDIV also (EOF-2; Fig. 5d). However, the explained 

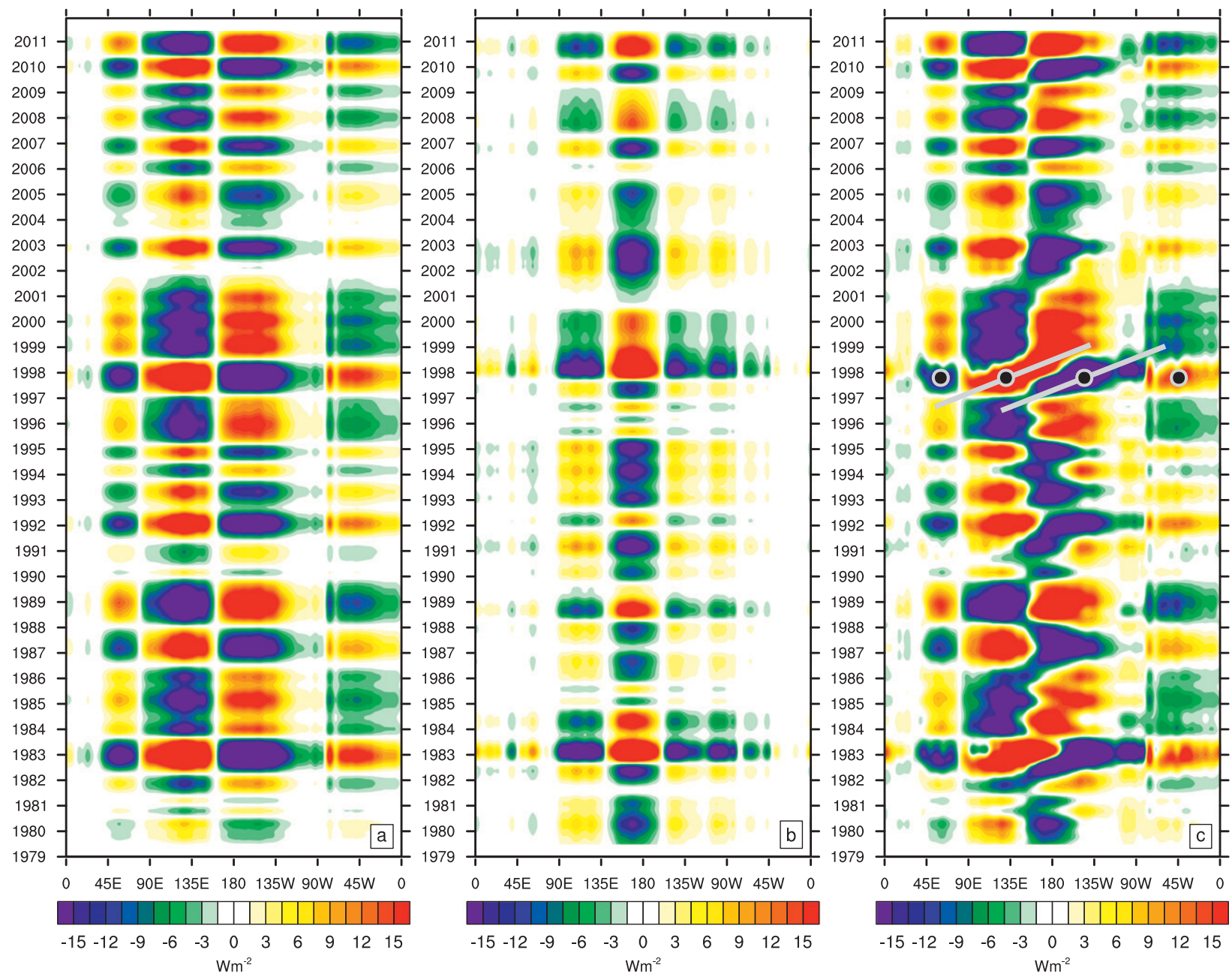

FIG. 7. Longitude-time Hovmöller plots of smoothed monthly anomalies of tropical LEDIV from ERA-I reconstructed from (a) EOF-1, (b) EOF-2, and (c) EOF-1 + EOF-2 and their respective PCs. Filled circles in (c) indicate the quadrupole anomaly response to the 1997/98 El Niño event. Gray lines indicate the eastward propagation of the main anomaly maxima.

variance of EOF-2 is less than 9\%. Hence, TEDIV anomalies and consequently anomalous net energy exchanges between ocean and atmosphere are relatively weak for El Niño Modoki conditions. The lead-lag relationships with Niño-3.4 and - TNI shown in Figs. $6 \mathrm{c}$ and $6 \mathrm{~d}$ are quite similar to those found by Trenberth et al. (2002b), who performed singular value decomposition (SVD) analyses of reanalyzed TEDIV and diabatic heating fields for 1979-2001.

The discussed LEDIV EOFs are significant according to North et al. (1982) at the $95 \%$ confidence level across all three reanalyses. TEDIV EOFs are significant only from ERA-I fields, while TEDIV EOF-1 and EOF-2 are not well separated in MERRA and CFSR data. We also examined cross correlations of both LEDIV and TEDIV PC-2 with the El Niño Modoki Index (as defined in Ashok et al. 2007) instead of TNI and the results were very similar.
Reconstructed LEDIV time series using EOF-1 and EOF-2, their respective PCs, and their sum are shown in Figs. 7a-c, respectively. Figure 7a resolves the quadrupole structures of tropical LEDIV anomalies with alternating signs and values exceeding $\pm 15 \mathrm{~W} \mathrm{~m}^{-2}$. This figure also makes clear that this signature is apparent nearly throughout the whole data period with alternating sign.

Anomaly series reconstructed from EOF-2 and PC-2 (Fig. 7b) shows the tripole anomaly structure related to El Niño Modoki. The center of moisture convergence during warm El Niño Modoki conditions (e.g., in 1982) is centered slightly west of the date line. This center lies between the two anomaly centers of EOF-1 in the Pacific region (Indo-Pacific warm pool and eastern Pacific). Anomaly values related to EOF-2 are generally smaller than those related to EOF-1. Qualitatively, the warm Modoki phase appears to last longer than the cold phase. 
The sum of the two reconstructed series is shown in Fig. 7c. It clearly resembles the coherent time-space structures already seen from Fig. 2b, with west-east transition of negative LEDIV anomalies for the strong El Niños in 1982/83, 1991/92, and 1997/98 but also westeast transition of positive anomalies related to cold ENSO events (e.g., prior to the 1999 or 2011 La Niñas). Reconstructed DSEDIV shows qualitatively the same with reversed sign (not shown). This means that we are able to reconstruct the main features of tropical energy divergence anomalies related to ENSO evolution from the first two EOFs and their respective PCs. This is in agreement with Trenberth and Smith (2006), who found for other fields such as temperature at different vertical levels that at least two EOFs are required to depict ENSO evolution.

\section{Discussion and conclusions}

The zonal structure and variability of the tropical energy budget has been investigated, employing data from third-generation ERA-I, MERRA, and CFSR. A distinct and robust response to ENSO can be found in the longitude-time variability of the energy divergences. LEDIV features anomalies with a pronounced quadrupole structure, with negative values over the central/ eastern Pacific and the Indian Ocean and positive anomalies over the Indo-Pacific warm pool as well as the Atlantic Ocean during warm events (the opposite applies for cold events). The main driver for this atmospheric response is positive SST anomalies over the eastern Pacific, which induce stronger than normal moisture convergence (i.e., negative LEDIV anomalies) and consequently latent heating due to precipitation anomalies in this region. The rising motion associated with these anomalies leads not only to a reversal of the Walker circulation and thus anomalous descending motion over the Indo-Pacific warm pool (i.e., weaker than normal rising motion) but also a descending branch over the tropical Atlantic (see, e.g., Klein et al. 1999). Circulation anomalies are directly reflected in LEDIV. The fourth pole is related to positive SST anomalies over the Indian Ocean, usually associated with warm ENSO events (see also Klein et al. 1999), leading to negative LEDIV and positive vertical motion anomalies. DSEDIV exhibits qualitatively the same response with reversed sign, but even enhanced magnitudes of the anomalies, because LEDIV and $\operatorname{Rad}_{S}$ (positive downward) are positively correlated. This quadrupole structure is also evident in the first EOF of tropical LEDIV (Fig. 7a). The peak phase of warm events is also the time when net surface fluxes contain a significant negative anomaly, with large contribution from stronger than normal evaporation over the central-eastern Pacific, leading to a positive TEDIV anomaly. As TOA net radiation perturbations are small, TEDIV anomalies are largely a manifestation of the ocean heat discharge phase as proposed by Jin (1997), which is maintained not only by poleward ocean heat transports but also by anomalous evaporative cooling of the ocean (see, e.g., Trenberth et al. 2002b).

However, LEDIV coupling to SST is not of the same strength everywhere. This becomes clear when considering the El Niño evolution composited over the three major warm ENSO events in 1982/83, 1991/92, and 1997/98. Around 15-18 months ahead of the respective peaks of these El Niños, LEDIV anomalies feature a quadrupole structure typical for La Niña conditions. Indeed, over the eastern tropical Pacific, leading negative SST anomalies are evident and a weak positive SST anomaly exists west of the date line (Fig. 4g). This anomaly arises from eastward advection of warm Indo-Pacific warm pool water, which extends farther in the following months, in support of the initialization of the next warm event (Sarachik and Cane 2010). However, at that time negative LEDIV anomalies (i.e., stronger than normal moisture convergence) extend to the west as far as $80^{\circ} \mathrm{E}$. This cannot be explained only from the small warm SST anomaly, which is located much farther to the east. Obviously, LEDIV is more weakly coupled to local SST over the Indo-Pacific warm pool than it is over the centraleastern Pacific. LEDIV anomalies over the Indo-Pacific warm pool compensate for LEDIV anomalies over the central-eastern Pacific, which in return are strongly SST driven. In the subsequent months, the initially small warm SST anomaly slowly propagates eastward until the mature El Niño phase begins developing some 6 months before the event peak.

Zebiak and Cane (1987) found that strongest ENSOrelated wind stress anomalies were around the date line, driving the eastward propagation of warm SST anomalies and also exciting the eastward propagating equatorial Kelvin waves that initialize El Niño events. These wind stress and SST anomalies are also associated with moisture divergence anomalies in that region. EOF-2 of LEDIV (Fig. 5b) depicts this transition state, with stronger than normal moisture convergence around the date line. PC-2 consistently shows strongest correlation with $-\mathrm{TNI}$ at lag $-3(r=0.8)$, indicating the atmosphere's leading role during this phase. Thus, the apparent eastward propagation of negative LEDIV anomalies (and correspondingly positive DSEDIV anomalies) associated with strong El Niño events (see, e.g., Fig. 2b) is due to the seamless transition between La Niña and El Niño, during which the atmospheric circulation alternately takes a leading and a responding part. The strong 1982/83 and 
1997/98 El Niños (and also others such as the 2009/10 event) show remarkable agreement regarding their spatiotemporal evolution, while other strong warm events evolve differently (Fig. 2), such as the 1991/92 event, which exhibits a much longer preceding central Pacific warming state. However, all ENSO events during the period covered are preceded by LEDIV and DSEDIV anomalies in the central Pacific 6-9 months prior to the respective event peaks (see also the significant cross correlations in Figs. 3b,c). Thus, energy budget anomalies related to both warm and cold events propagate from west to east. This result is distinct from (but not necessarily contradictory to) that of McPhaden and Zhang (2009), who found east-to-west propagation of La Niña SST anomalies.

The total energy picture is different. Compared to LEDIV and DSEDIV, the TEDIV response to ENSO is, in terms of magnitude, generally much weaker, mainly because latent heating from anomalous precipitation is realized as DSE and thus does not alter total energy. TEDIV anomaly series show a dipole with maxima over the Indo-Pacific warm pool and central-eastern Pacific during ENSO peak phases. Positive TEDIV anomalies (mainly driven by anomalous $F_{S}$ ) over the centraleastern Pacific during warm ENSO phases correspond to the discharge phase, while negative anomalies over the central/eastern Pacific indicate the recharge phase. Thus, atmospheric TEDIV is in phase with equatorial oceanic warm water volume (i.e., the water above the thermocline within $5^{\circ} \mathrm{S}-5^{\circ} \mathrm{N}$ ) discharge (see Meinen and McPhaden 2000). As already emphasized by MH12, strong compensation occurs between central and eastern Pacific and Indo-Pacific warm pool, leading to relatively weak TEDIV (and thus $F_{S}$ ) anomalies on the Pacific zonal average, which can reach $10 \mathrm{~W} \mathrm{~m}^{-2}$ during strong warm events (corresponding to an total energy export anomaly of $\approx 0.8 \mathrm{PW}$ ). For the full zonal average $\left(360^{\circ}\right)$, maximum total energy export anomalies reach $3-4 \mathrm{~W} \mathrm{~m}^{-2}$ (corresponding to $\approx 0.6 \mathrm{PW}$ ).

The transition phase however, which is clearly resolved in both LEDIV and DSEDIV (and also their second EOF and respective PC), while detectible in TEDIV, exhibits marginal variance ( $<9 \%$ in ERA-I). Thus, in the atmosphere, this phase of ENSO is mainly a change in circulation but the signal in total energy divergence is weak. The reason for this might be the decreasing surface wind speed around the date line because of easing trade winds, damping positive evaporation anomalies stemming from already increased SSTs in that region [as also speculated by Kumar and $\mathrm{Hu}$ (2012)]. This could explain the comparatively weak ocean-atmosphere coupling in terms of energy exchange during this phase. Hence, central Pacific warming events (El Niño Modoki state; e.g., in 2002 or 2007), which resemble EOF-2 of LEDIV and DSEDIV, respectively, lead to very weak alteration of the total energy budget compared to canonical El Niños. In this context, the observed spatiotemporal coherence of energy budget anomalies suggests that El Niño Modoki is part of the overall evolutionary patterns of ENSO and represents a transition state between cold and warm ENSO phases. This is seen when all months of the year are considered together, and thus the annual cycle may also play a role. Hence, the fact that El Niño Modoki is depicted by a single EOF mode should not be overinterpreted.

In conclusion, the diagnostic methods presented herein are useful for monitoring ENSO and will be invaluable in validating climate models. The observed redistribution of energy during the ENSO cycle needs to be captured by climate models in order to realistically simulate global teleconnections. For instance, a realistic simulation of the zonal structure of LEDIV in response to ENSO (which in turn is dependent on realistic SST anomaly patterns) is necessary for a reasonable depiction of observed teleconnections such as ENSO-related droughts over Australia. Cross-correlation or EOF patterns, as presented in sections $3 \mathrm{c}$ and $3 \mathrm{e}$, could serve as benchmarks when investigating energy budgets in climate models.

Moreover, it is planned to extend the current analysis retrospectively, as new reanalyses covering the presatellite era become available including the Twentieth Century Reanalysis (Compo et al. 2011) and the soon to be released Japanese Reanalysis 55 and ERA-Clim pilot reanalyses. We also expect that future coupled reanalyses that include interactions with the deep ocean will help to further improve the presented diagnostics.

Acknowledgments. This work has been financially supported by Grant P21772-N22 of the Austrian Science Funds (FWF) and by the Graduate Visitor program of the Advanced Study Program (ASP) of NCAR. This research is partially sponsored by NASA Grant NNX09AH89G.

\section{REFERENCES}

Alexander, M. A., N. C. Lau, and J. D. Scott, 2004: Broadening the atmospheric bridge paradigm: ENSO teleconnections to the tropical west Pacific-Indian Oceans over the seasonal cycle and to the North Pacific in summer. Earth's Climate: The Ocean-Atmosphere Interaction, Geophys. Monogr., Vol. 147, Amer. Geophys. Union, 85-103.

Ashok, K., S. K. Behera, S. A. Rao, H. Weng, and T. Yamagata, 2007: El Niño Modoki and its possible teleconnection. J. Geophys. Res., 112, C11007, doi:10.1029/2006JC003798.

Chiodo, G., and L. Haimberger, 2010: Interannual changes in mass consistent energy budgets from ERA-Interim and 
satellite data. J. Geophys. Res., 115, D02112, doi:10.1029/ 2009JD012049.

Clarke, A. J., 2008: An Introduction to the Dynamics of El Niño and the Southern Oscillation. Academic Press, $324 \mathrm{pp}$.

Compo, G. P., and Coauthors, 2011: The Twentieth Century Reanalysis Project. Quart. J. Roy. Meteor. Soc., 137, 1-28.

Cullather, R. I., and M. G. Bosilovich, 2012: The energy budget of the polar atmosphere in MERRA. J. Climate, 25, 5-24.

Dee, D. P., and S. Uppala, 2009: Variational bias correction of satellite radiance data in the ERA-Interim reanalysis. Quart. J. Roy. Meteor. Soc., 135, 1830-1841, doi:10.1002/qj.493.

— , and Coauthors, 2011: The ERA-Interim reanalysis: Configuration and performance of the data assimilation system. Quart. J. Roy. Meteor. Soc., 137, 553-597, doi:10.1002/qj.828.

Fasullo, J. T., and K. E. Trenberth, 2008a: The annual cycle of the energy budget. Part I: Global mean and land-ocean exchanges. J. Climate, 21, 2313-2325.

— Meridional structures and poleward transports. J. Climate, 21, 2297-2312.

Hantel, M., and Coauthors, 2005: Observed Global Climate. Landolt Börnstein New Series, Vol. 6, Springer, 588 pp.

Huffman, G. J., R. F. Adler, D. T. Bolvin, and G. J. Gu, 2009: Improving the global precipitation record: GPCP version 2.1. Geophys. Res. Lett., 36, L17808, doi:10.1029/2009GL040000.

Jin, F. F., 1997: An equatorial ocean recharge paradigm for ENSO. Part I: Conceptual model. J. Atmos. Sci., 54, 811-829.

Klein, S. A., B. J. Soden, and N. C. Lau, 1999: Remote sea surface temperature variations during ENSO: Evidence for a tropical atmospheric bridge. J. Climate, 12, 917-932.

Kumar, A., and Z. Z. Hu, 2012: Uncertainty in the ocean-atmosphere feedbacks associated with ENSO in the reanalysis products. Climate Dyn., 39, 575-588.

Lorenz, E., 1967: The Nature and Theory of the General Circulation of the Atmosphere. WMO, $161 \mathrm{pp}$.

Mayer, M., and L. Haimberger, 2012: Poleward atmospheric energy transports and their variability as evaluated from ECMWF reanalysis data. J. Climate, 25, 734-752.

McPhaden, M. J., 1999: Genesis and evolution of the 1997-98 El Niño. Science, 283, 950-954, doi:10.1126/science.283.5404.950.

— of ENSO sea surface temperature anomalies. Geophys. Res. Lett., 36, L13703, doi:10.1029/2009GL038774.

Meinen, C. S., and M. J. McPhaden, 2000: Observations of warm water volume changes in the equatorial Pacific and their relationship to El Niño and La Niña. J. Climate, 13, 3551-3559.

North, G. R., T. L. Bell, R. F. Cahalan, and F. J. Moeng, 1982: Sampling errors in the estimation of empirical orthogonal functions. Mon. Wea. Rev., 110, 699-706.

Okumura, Y. M., and C. Deser, 2010: Asymmetry in the duration of El Niño and La Niña. J. Climate, 23, 5826-5843.
Peixoto, J. P., and A. H. Oort, 1992: Physics of Climate. American Institute of Physics, $520 \mathrm{pp}$.

Rienecker, M. M., and Coauthors, 2011: MERRA: NASA's Modern-Era Retrospective Analysis for Research and Applications. J. Climate, 24, 3624-3648.

Saha, S., and Coauthors, 2010: The NCEP Climate Forecast System Reanalysis. Bull. Amer. Meteor. Soc., 91, 1015-1057.

Sarachik, E. S., and M. A. Cane, 2010: The El Niño-Southern Oscillation Phenomenon. Cambridge University Press, 384 pp.

Trenberth, K. E., and D. P. Stepaniak, 2001: Indices of El Niño evolution. J. Climate, 14, 1697-1701.

$\longrightarrow$, and _ 2003a: Covariability of components of poleward atmospheric energy transports on seasonal and interannual timescales. J. Climate, 16, 3691-3705.

$\longrightarrow$, and —, 2003b: Seamless poleward atmospheric energy transports and implications for the Hadley circulation. J. Climate, 16, 3706-3722.

— the tropics: Different flavors of El Niño. J. Climate, 19, 49564973.

—_ and _ 2008: Atmospheric energy budgets in the Japanese reanalysis: Evaluation and variability. J. Meteor. Soc. Japan, 86, 579-592, doi:10.2151/jmsj.86.579.

— The Russian heat wave and other climate extremes of 2010. J. Geophys. Res., 117, D17103, doi:10.1029/2012JD018020.

_ J. J. Caron, D. Stepaniak, and S. Worley, 2002a: Evolution of El Niño-Southern Oscillation and global atmospheric surface temperatures. J. Geophys. Res., 107 (D8), doi:10.1029/ 2000JD000298.

— D. P. Stepaniak, and J. M. Caron, 2002b: Interannual variations in the atmospheric heat budget. J. Geophys. Res., 107 (D8), doi:10.1029/2000JD000297.

— climate change. Climate Change 2007: The Physical Science Basis, S. Solomon et al., Eds., Cambridge University Press, 235-336.

_ Bull. Amer. Meteor. Soc., 90, 311-323.

$\longrightarrow, \ldots$, C. O'Dell, and T. Wong, 2010: Relationships between tropical sea surface temperature and top-of-atmosphere radiation. Geophys. Res. Lett., 37, L03702, doi:10.1029/ 2009GL042314.

_- J. Fasullo, and J. Mackaro, 2011: Atmospheric moisture transports from ocean to land and global energy flows in reanalyses. J. Climate, 24, 4907-4924.

Wallace, J. M., and J. Shukla, 1983: Numerical simulation of the atmospheric response to equatorial Pacific sea surface temperature anomalies. J. Atmos. Sci., 40, 1613-1630.

Zebiak, S. E., and M. A. Cane, 1987: A model El Niño-Southern Oscillation. Mon. Wea. Rev., 115, 2262-2278. 